\title{
Curiosité: Inquiry-Based Instruction and Bilingual Learning
}

\author{
Cheryl M. McElvain ${ }^{1, *}$ \& Heidi A. Smith ${ }^{2}$ \\ ${ }^{1}$ Arts and Basic Teacher Credential Programs, Department of Education, Santa Clara University, USA \\ ${ }^{2}$ Teacher and English Curriculum Coordinator, International School of the Peninsula, USA \\ *Correspondence: 15860 La Porte Ct., Morgan Hill, CA 95037, USA. Tel: 1-408-828-1671. E-mail: \\ cmcelvain@scu.edu
}

Received: September 1, 2016 Accepted: September 24, $2016 \quad$ Online Published: October 16, 2016

doi:10.5430/jct.v5n2p63

URL: http://dx.doi.org/10.5430/jct.v5n2p63

\begin{abstract}
The issues that prompt this study are based on current research indicating the positive effects of inquiry learning on the cognitive development of children. The purpose of this case study was to understand the effects of inquiry learning on the academic achievement and bilingual verbal ability of 5th grade bilingual students in a French/English dual immersion program. The treatment group of students completed research projects through a guided inquiry learning approach, while the control group experienced the traditional problem solving research approach. Initial findings report a significant mean increase in mathematical reasoning, bilingual verbal ability, higher motivation to learn, and increased self-efficacy in the treatment versus the control group of students.
\end{abstract}

Keywords: inquiry-based instruction; bilingual children; bilingual verbal ability; bilingual learning; self-regulated learning

Curiosity engages learning. Children naturally question, and form conclusions when they explore their environment. Research on the cognitive development of children suggests that when learners are curious they develop explanations based on observable patterns that lead to new discovery, and more effective learning (Williams \& Lombrozo, 2010). Related studies on curiosity, and memory have also found that when children are given answers to questions that are perplexing they remember them better, indicating that learning increases with curiosity (Litman, 2005).

\section{Introduction}

This study investigates the effect of inquiry-based instruction on the cognitive and verbal development of bilingual children. Although it is well documented that cognitive skills acquired in a child's first language (L1) positively transfer to thinking in a second language (L2) (De Groot, 2011; Laija-Rodríguez, Ochoa, \& Parker, 2006; Yamashita, 2002), finding the best instructional approaches to promote the acquisition of bilingual verbal, and cognitive ability continues to be a challenge for many bilingual teachers (Alanís, 2011). Recent studies of effective language development approaches for English language learners have reported positive results using inquiry-based approaches in math and science instruction (Weinburgh et al., 2014), however there is limited research exploring the effects of inquiry-based instruction with bilingual children (Moses, Busetti-Frevert, Pritchard, 2015) in other subject areas (Chu, 2009).

The purpose of this case study was to understand how inquiry-based instruction affects the academic achievement and bilingual verbal ability of thirty-two $5^{\text {th }}$ grade students in a French dual immersion program. Bilingual verbal ability (BVA) is the "unique combination of cognitive and academic language abilities possessed by bilingual individuals” (Munoz-Sandoval, et al., 1998, p. 1).

The study utilized a treatment and control group to explore the cognitive, linguistic, and psychosocial effects of inquiry-based instruction compared to traditional problem-solving instruction. No pilot study was conducted prior to this investigation. A mixed methods approach was utilized to examine the following questions:

1. How does inquiry-based instruction affect the academic achievement and bilingual verbal development of French/English speaking $5^{\text {th }}$ grade students compared to a control group receiving traditional problem-solving instruction? 
2. How do the students in the treatment group perceive the effects of inquiry learning on their language and cognition compared to the control group receiving traditional problem-solving instruction?

\section{Literature Review}

Inquiry-based learning utilizes a child's natural curiosity to explore new information that is meaningful to the learner. It is a cyclical process by which the learner selects a topic or question, explores multiple sources of information with the intent to find and support a focused perspective, shares the discovery with others, and finally reflects on the process as a whole. Research reveals that inquiry-based learning can heighten a child's research skills (McNally, 2005), subject knowledge, writing (Chu, Chow, Luk, Cheung, \& Sit, 2007) and motivation to read (Chu, Tse, Loh \& Chow, 2011).

Recent studies in science education exploring the effects of inquiry-based instruction on the academic achievement in of bilingual children have been positive. Amaral, Garrison, and Klentschy, (2002) examined the effects of inquiry-based science instruction on $4^{\text {th }}$ and $6^{\text {th }}$ grade English language learners (ELL) in California. Results reported an increase in children's science knowledge as well as their reading, writing, and mathematics achievement as demonstrated on state standardized tests. In their investigation of effective science teaching for ELLs, Stoddart, Bravo, Solis, Mosqueda, and Rodriguez (2011) reported that instruction for bilinguals utilizing inquiry-based approaches provided an effective context for developing academic language and literacy skills. This finding was supported in Westervelt's (2007) study that explored the effects of scaffolded inquiry (Maata, Dobb, \& Ostlund, 2006) on ELL students' life science concepts. Recognizing the developmental stages of inquiry learning the teacher scaffolded students' conceptual understanding through a series of outdoor walks, which developed their academic science vocabulary. Results reported an increase in the students' understanding of academic language in their mainstream science classes.

\subsection{Theoretical Constructs}

Dewey's (1916) foundational Democracy and Education provides key constructivist understandings utilized in the inquiry approach. Espousing whole child learning, Dewey posited, "That education is not an affair of telling and being told but an active and constructive process...” (p. 46). He suggested that it's only when a parent or teacher provides conditions that encourage children to wrestle with their own questions do they truly begin to think. Inquiry-based learning perceives information as the working capital that motivates the learner to explore. It formulates learning as a problem posing cycle that is guided by reflection and leads to higher-level understanding.

Recent research in neuroscience confirms Dewey's theoretical constructs providing further support for inquiry-based learning. Studies have shown increased connectivity and exuberance in the brain when exposed to new stimuli or problem solving (Lee, 2011). The heightened emotional response experienced in inquiry-based learning causes learners to investigate their environment with the enhanced receptivity needed to drive critical thinking and more effectively facilitate the encoding of new information.

\subsection{Stripling's Model of Inquiry}

The inquiry-based instructional program utilized in this study was guided by cyclical elements of inquiry found in the Stripling (2003) Model of Inquiry. Originally intended to frame the learning of information technology the model incorporates six phases in which the students connect, wonder, investigate, construct, express and reflect on their learning (see Figure 1). Throughout each phase students actively process information with teacher guidance and feedback from peers, rather than passively receiving facts through a transmission oriented model of instruction (Castronova, 2002). 


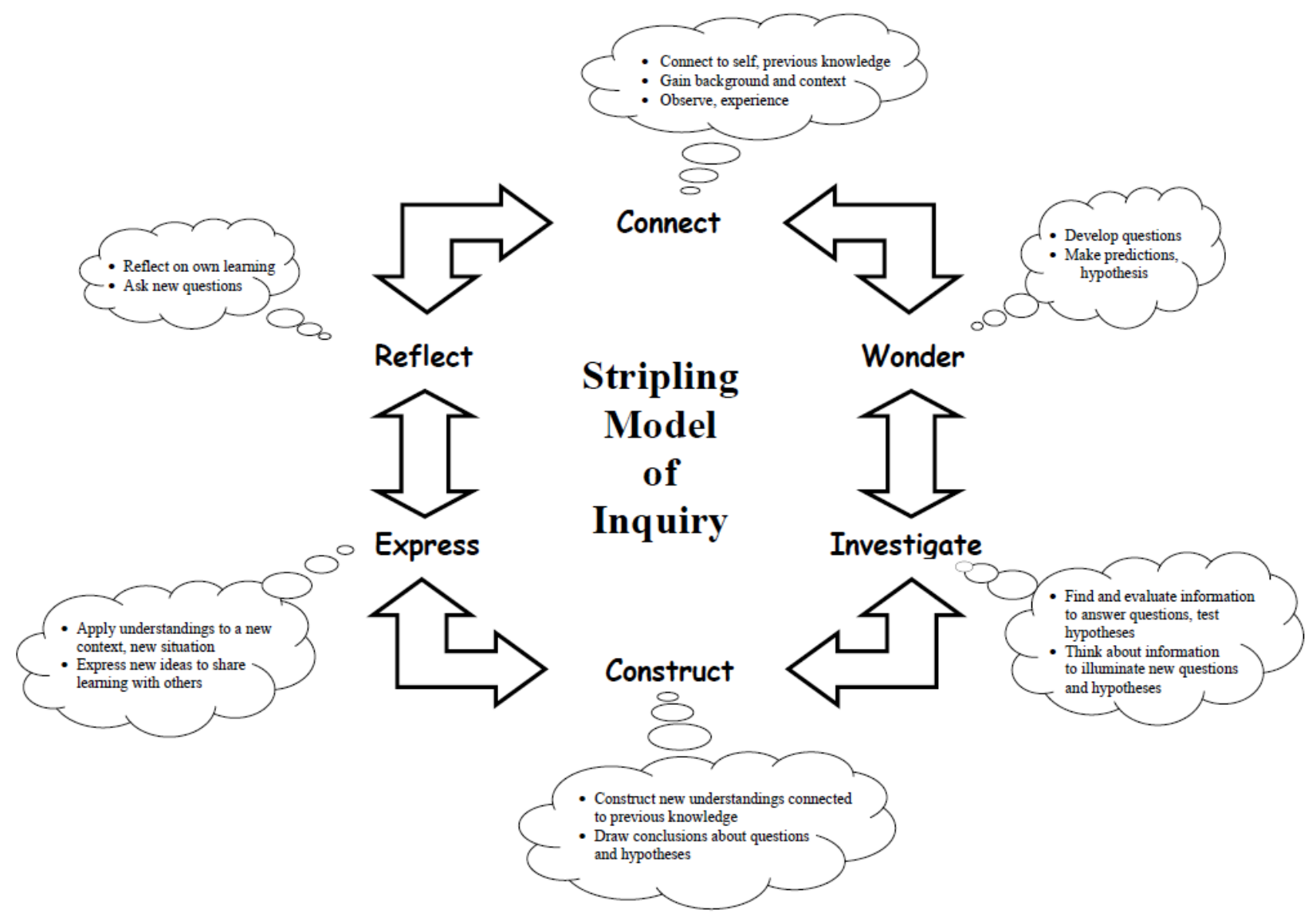

Figure 1. Stripling Model of Inquiry

SOURCE: Used with permission from Stripling, B. (2010). Teaching students to think in the digital environment:

Digital literacy and digital inquiry. School Library Monthly, 26(8), 16-19.

Stripling juxtaposes the processes between inquiry-based and problem-solving research processes. She notes that in the traditional problem-solving model the learner is asked to find an answer to an already existent problem introduced by the teacher. The process is controlled, and usually results in a written report submitted to the teacher. The cognitive processing is minimal because learners are typically copying what others have deduced.

In contrast, the inquiry-based learning model starts with a student-posed question. This question is posed during the wonder phase in which students also make predictions and form hypotheses. Student inquiry continues to guide a recursive process in the investigate phase in which the student researches, evaluates, and tests new information.

When students enter the construct phase, they consider new learning in light of their previous understanding, and begin to draw conclusions. As students apply their understandings to new contexts, and situations they are invited to share their learning with others in the express phase.

When sharing is complete students begin to contemplate about what they have learned during the reflect phase through student journals, small group discussions, or individual teacher conferences. During the final connect phase, students gain a perspective on their new learning and how it relates to the world around them.

\section{Method}

\subsection{Participants}

This ten-month study observed the instructional effects of inquiry-based learning in an English/History Social Science class taught concurrently with a more traditionally structured class from September to June. Thirty-two, fifth-grade bilingual children volunteered to participate in the study. The convenience sample was divided into two groups, and randomly assigned to a teacher with an attempt to equalize gender, and language representation. The 
students assigned to be part of the treatment were placed in the inquiry-based classroom for two block periods per day. The remaining fifth graders were assigned to a control classroom taught by a different teacher during the same period.

Both the treatment and control groups had an equal number of students $(\mathrm{N}=16)$. There were seven males and nine females in the treatment group, and six males and ten females in the control group. Each group had nine native English speakers, five native French speakers, and two native Arabic speakers. All of the children were performing at grade level or above as reported on their Comprehensive Testing Program 4 (CTP4) English, and French proficiency tests. All subjects had participated in the French dual immersion program for six years.

The majority of the students came from high socioeconomic backgrounds with college-educated bilingual parents. When asked about language use the children reported using French and English for different purposes. All of the children in both the treatment and control groups reported using French with their Francophone parents and friends in school. The children in both groups reported using English with parents, siblings, friends, and in the English portion of the school day.

Two White, female teachers participated in the study. Both were native English speakers with a basic knowledge of conversational French, however all of their instruction was in English. The teachers co-planned and taught the same English/History Social Science concepts used in this study and submitted their lessons to the researchers during an initial site visit. The researchers visited two times per month throughout the year to ensure the fidelity of each teacher's instructional plan.

Because research instruction is an important part of the English/History Social Science curriculum, the research instructional themes were jointly developed and taught in each classroom in tandem. Both teachers spent the same number of hours in research instruction with their students. The research pedagogical approach was the only element that differed between both classrooms.

\subsection{Setting}

The study was conducted in a private international PreK $-8^{\text {th }}$ grade school with 580 students located in Northern California. The French immersion program operates on trimester model. Each trimester includes three months of instruction that promotes bilingualism, and international perspectives of the world. The students spend approximately 80\% of their instructional time in French, and 20\% in English. All content areas are taught in French. The English portion of the curriculum focuses on English-Language Arts, and History-Social Science. Each student is provided access to a laptop and extensive resources for research activities.

\subsection{Procedure}

This study investigated the effects of two diverse instructional approaches offered during the English Language Arts/Social Studies time block of two hours per day, eight hours per week. Students in both the control and treatment classes independently worked on research projects approximately two hours per week. Although all of the students in the study were expected to report in English, both teachers gave them the choice to investigate research sources in either French or English.

The control group of $5^{\text {th }}$ graders experienced traditional problem solving instruction for their research assignments. The pedagogy followed the historical transmission model of learning in which students were passive recipients of teacher knowledge (Copsey Haydey, Zakaluk, \& Straw, 2010). The research lessons were teacher directed. Students were not given the opportunity to develop their own research questions, nor did they choose their own research topics. The teacher assigned a topic as students utilized resources from the library, took notes, wrote a report, or orally presented their findings.

The treatment group of students experienced an interdisciplinary approach to Stripling's (2003) inquiry learning model. Each trimester students participated in the following inquiry-based learning activities: 1) a mini inquiry, 2) a curricular inquiry, and 3) an open inquiry (see Figure 2). 


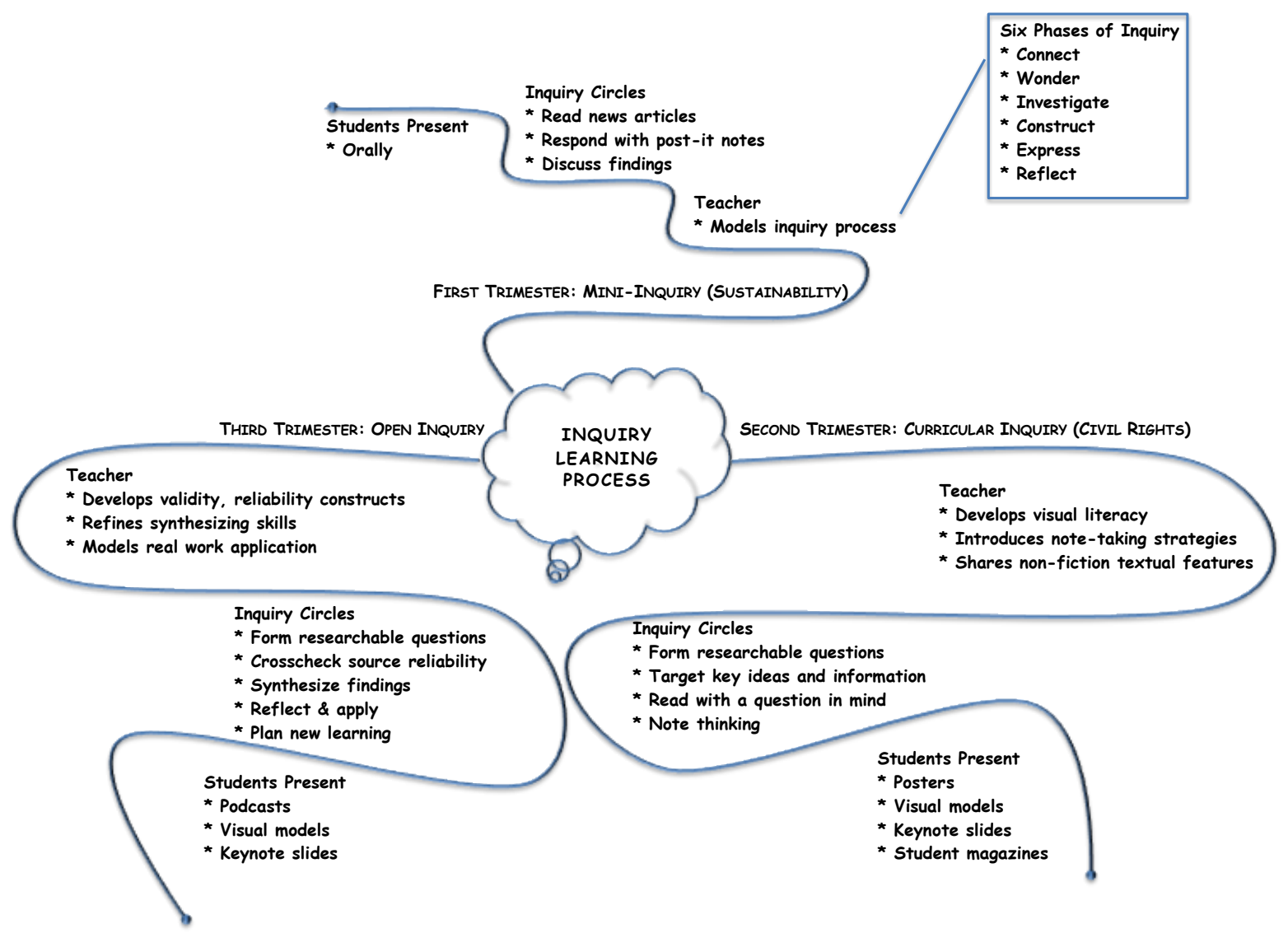

Figure 2. Treatment Group Inquiry Learning Plan

At the beginning of first trimester the teacher modeled inquiry research through a mini-inquiry using selected news magazine articles related to sustainability. The students were asked to research sustainability practices such as alternative energy resources in any U.S. state of their choice. In guided inquiry circles the students formed researchable questions, read multiple non-fiction text sources, and used post-it notes to record their thinking. They met with their research group weekly to discuss their responses as they worked through each phase of the inquiry. Students presented their findings to the class in an oral presentation.

Throughout the mini-inquiry the teacher guided the students through all six phases of Stripling's inquiry process. She engaged students in the connect phase by relating the topic to their preexisting knowledge of themselves, others, and the world around them. The teacher also spent time building students' background knowledge as they began to form their own researchable questions. Through the wonder phase, the teacher guided, and deepened the students' question constructions while encouraging them to hypothesize and form predictions. This phase activated the students' schema as they began to process, and relate new information to prior learning (Milligan, 1979). When the students entered the investigate phase they learned research strategies that facilitated comprehension such as how to search for information, discover answers, take notes, and read with a question in mind. Throughout the construct phase the teacher intensified the students' research skills by teaching them how to draw conclusions, infer, find patterns, understand multiple points of view, evaluate sources, and clarify their thinking. The students learned how to synthesize their thinking as they read for the gist and engaged in guided small group discussions and debates. Finally, in the express and reflect phases, the students shared their knowledge with a real audience. They demonstrated new learning, and understanding through an oral presentation. Students reflected on their knowledge, posed new questions, and considered how learning affected their personal beliefs and behaviors.

In the second trimester the teacher used the theme of social justice to engage students in a curricular inquiry on civil rights. Students continued to meet in their inquiry circles reading historical nonfiction, and a historically related whole class novel. The teacher focused her lessons on visual literacy, various note taking strategies, understanding 
features in non-fiction text, and utilized interactive read-alouds to model text annotations, inferencing, and synthesizing. The students reported their research findings via oral presentation, Keynote slides, posters, visual models, and student generated magazines.

During the third trimester the teacher introduced an open inquiry project in which the students were asked to identify an essential question derived from anything they had read or experienced throughout the year. Borrowing from Wiggins and McTighe's (1998) enduring understandings essential questions were defined as focused, authentic queries that were researchable, and essential to new learning. Student inquiry circles were organized around essential questions as they read non-fiction texts, and historical fiction. The essential question came from culminating thoughts recorded in their inquiry journal. Students read a multiple text genres from a variety of sources. The teacher's lessons taught students how to evaluate the validity, reliability, and usefulness of the information they encountered. At the end of the year students shared their learning via an audio recorded essay podcast, Keynote presentation, poster, or three dimensional model that was presented to the class, and their parents.

\subsection{Measures}

This 10-month study used a mixed methods approach to ascertain the effects of inquiry-based learning on the academic achievement, bilingual development, and student learning perceptions of thirty-two, $5^{\text {th }}$ grade students assigned to a treatment or control instructional environment. Triangulated data were collected from the Educational Records Bureau's (2002) Comprehensive Testing Program 4, (CTP4), the Bilingual Verbal Ability Test (BVAT), and 2 student questionnaires throughout the year (see Figure 3). Although the quantitative measures of this study focused on the academic outcomes of inquiry-based learning, the qualitative measures helped the researchers understand the total effects of the program.

Figure 3. Instrument Administration Timeline for Treatment and Control Groups

\begin{tabular}{cll}
\hline \multirow{2}{*}{ Fall } & \multicolumn{1}{c}{ Treatment } & \multicolumn{1}{c}{ Control } \\
& CTP 4 & CTP 4 \\
& BVAT & BVAT \\
\multirow{5}{*}{ Spring } & Questionnaire \#1 (pretest) & Questionnaire \#1 (pretest) \\
& CTP 4 & CTP 4 \\
& BVAT & BVAT \\
& Questionnaire \#1 (posttest) & Questionnaire \#1 (posttest) \\
& Questionnaire \#2 & Questionnaire \#2 \\
\hline
\end{tabular}

NOTE: Three additional questions were added to Questionnaire \#1 (posttest) for the treatm group to help researchers ascertain student perceptions of inquiry instruction.

For this study the CTP 4 norm-referenced achievement test helped the researchers understand how inquiry-based learning affected the overall academic achievement of the treatment group compared to the control group in multiple cognitive domains. Fall and spring test scores were ascertained from the treatment and control groups to determine achievement gains. The students took multiple-choice subtests in verbal reasoning, vocabulary, reading comprehension, writing mechanics, writing concepts and skills, quantitative reasoning, and mathematical reasoning. The reasoning assessments in English-language arts and mathematics compared what students knew with how well they could use higher-level thinking skills to solve problems. The researchers chose to use the CTP 4 because it was standardized on a national sample of 38,000 public and private school students and reported an internal consistency reliability in the range of 0.78 (Fouratt \& Owen, 2004).

The researchers chose to use the Bilingual Verbal Ability Tests (BVAT) because it is the only generally accepted bilingual instrument available to assess skills associated with bilingual intelligence (Ortíz, 2002). The three BVAT tests have their origins from the Woodcock Language Proficiency Battery-Revised (WLPB-R) (Woodcock, 1991) and the Woodcock-Johnson-Revised Tests of Cognitive Ability (WJ-R COG) (Woodcock \& Johnson, 1989). The comprehensive testing manual reports that the median BVA reliability observed in 1988 for 542 bilingual subjects was .84 (Munoz-Sandoval, et al., 1998). Concurrent, predictive, and construct validity studies of the BVAT report a correlation coefficient within the .7 to .9 range. 
Native speakers of English and French administered the oral version of the English and French BVAT in the fall and spring. The procedures called for the administration of the following three subtests in the English language first, and French second: (a) Picture Vocabulary, (b) Oral Vocabulary, and (c) Verbal Analogies. The overall subtest score was based on the student's bilingual knowledge and reasoning skills.

Student participants in both the treatment and control groups were given two questionnaires administered in the fall and spring to ascertain perceptions of their respective instructional programs. All $(\mathrm{N}=32)$ students in both groups responded to both surveys in English.

The first short answer questionnaire narratively assessed students' perceptions of learning, inquiry research, and bilingual cognition. The students were asked the following questions: (1) What is your favorite and least favorite way of learning? (2) What does it mean to do research? Have you researched an interesting subject? (3) What is the biggest challenge you currently face in bilingual learning? How is research in two languages difficult? Two additional questions were added to the spring questionnaire for the treatment group only: (1) What did you learn by doing inquiry research? (2) What did you like best/least about inquiry learning?

A second questionnaire administered in the spring utilized a short answer response format to help the researchers understand students' perceptions of the research activities they had experienced in both the treatment and control groups. The Likert-type response was based on a 5-point scale ranging from 1 (strongly agree) to 5 (strongly disagree). The students were asked to respond to the following statements: (1) My research activities helped me learn. Give examples. (2) My research activities influenced my motivation to learn. Give examples.

\subsection{Data Analysis}

The following methods were used to analyze the data identifying the cognitive and psychosocial impact of inquiry-based learning on the academic achievement and bilingual cognitive development of a treatment group of $5^{\text {th }}$ grade students compared to their control peer group. Academic achievement and language development data were analyzed using repeated measures analysis of variance (ANOVA) test of within-subject contrasts for each CTP 4 subtest and the BVAT.

Content analysis and descriptive statistics were used to analyze emerging themes from the student questionnaires. The researchers examined responses collected from two questionnaires. Questionnaire \#1 was initially divided into two corpus units separating the treatment and control groups. The questions were categorized into three areas of student perception: (a) learning, (b) research, and (c) bilingual cognition. Each answer set was coded separately into themed meaning units and analyzed using Giorgi's (1975) empirical phenomenological method of analysis. This method analyzes texts by looking for natural meaning units and discovering emerging themes. The technique utilized for generating meaning was taken from one of thirteen such strategies developed by Miles and Huberman (1994). The researchers attempted to read each student's answer without prejudice when thematizing their statements. Essential nonredundant themes were synthesized into a descriptive statement in order to condense the expressed meanings into more specific understandings of student perceptions. When substantive differences in interpretation arose, the researchers worked them together into a dialogue leading to an intersubjective agreement of .92 (Krippendorff, 1980).

Questionnaire \#2 was a Likert-type, short answer form that was distributed to both groups in the late spring. The researchers sorted the corpus by control and sample group responses, and then tallied the Likert-type items using descriptive and summary statistics reporting numbers, percentages, and means of student responses. The researchers analyzed the paired short answer responses accompanying this questionnaire using a priori coding (Weber, 1990). They coded the field notes into recording units that were sorted into the following categories: (a) student learning, (b) student successes, (c) student challenges. When substantive differences in interpretation were found, the researchers negotiated a constructive dialogue, and resolved differences leading to an intersubjective agreement of .86 (Krippendorff, 1980).

\section{Results}

The results identifying the cognitive and psychosocial impact of inquiry-based learning on the academic achievement and bilingual verbal ability of the treatment group compared to the control group are presented as they relate to the two research questions posed for this study.

\subsection{Research Question \#1}

How does inquiry-based instruction affect the academic achievement and bilingual verbal development of 
French/English speaking $5^{\text {th }}$ grade students compared to a control group receiving traditional problem solving research instruction?

Table 1 presents the pretest (T1) and posttest (T2) results of the CTP4 and BVAT scores for the treatment and control groups. The means reported for the CTP4 Mathematics subtest indicated that the students receiving inquiry-learning instruction made significant gains in Mathematical Reasoning (T1 $M=63.6, S D=14.4, \mathrm{~T} 2 M=$ 73.0, $S D=12.3$ ), compared to the control group of students (T1 $M=68.3, S D=14.0$, T2 $M=64.4, S D=18.1$ ). A repeated measures ANOVA revealed that on the tests of within-subject contrasts there was a significant interaction in favor of the treatment group $F(1,27)=12.76, \mathrm{p}<.05$. The partial $\eta^{2}$ indicated that the interaction accounted for $32 \%$ of the variance in scores.

Table 1 also suggests that the bilingual verbal ability (BVA) reported on the BVAT for the treatment group increased at a faster rate (T1 $M=82.4, S D=16.8, \mathrm{~T} 2 M=95.2, S D=6.7$ ) than the control group (T1 $M=90.2, S D=12.4$, T2 $M=95.2, S D=5.7)$. On tests of within-subject contrasts, the repeated measures ANOVA analysis revealed that growth in bilingual verbal ability for the treatment group over time was statistically significant, $F(1,30)=4.22$, p $<.05$.

Table 1. Repeated Measures ANOVA for Mean CTP 4/BVAT Scores (with Standard Deviations in Parentheses)

\begin{tabular}{lrlllllll}
\hline Category & \multicolumn{2}{c}{$\mathrm{T}$} & \multicolumn{2}{c}{$\mathrm{C}$} & $d f$ & $F$ & $\eta^{2}$ & $p$ \\
\hline CTP4 Subtests & $\mathrm{T} 1$ & $\mathrm{~T} 2$ & $\mathrm{~T} 1$ & $\mathrm{~T} 2$ & & & & \\
\hline 1 - Verbal Reasoning & $3.2(1.2)$ & $2.9(.9)$ & $3.0(.9)$ & $2.6(1.5)$ & 1 & .14 & .005 & .71 \\
2 - Vocabulary & $2.6(1.2)$ & $2.2(1.3)$ & $2.1(1.4)$ & $2.3(1.5)$ & 1 & 2.51 & .07 & .13 \\
3 - Reading Comprehension & $2.9(1.3)$ & $3.0(1.4)$ & $2.9(1.4)$ & $2.4(1.1)$ & 1 & 1.92 & .06 & .18 \\
4 - Writing Mechanics & $2.4(1.0)$ & $1.9(.8)$ & $2.6(1.4)$ & $1.9(1.3)$ & 1 & .16 & .005 & .69 \\
5 - Writing Concepts/Skills & $3.2(1.3)$ & $3.2(1.4)$ & $2.5(1.3)$ & $2.8(1.3)$ & 1 & .54 & .02 & .47 \\
6 - Quantitative Reasoning & $2.2(1.1)$ & $2.0(1.0)$ & $2.3(1.3)$ & $1.7(1.4)$ & 1 & 2.52 & .08 & .12 \\
7 - Mathematical Reasoning & $63.6(14.4)$ & $73.0(12.3)$ & $68.3(14.0)$ & $64.4(18.1)$ & 1 & 12.76 & .32 & $.001^{*}$ \\
BVAT & $82.4(16.8)$ & $95.2(6.7)$ & $90.2(12.4)$ & $95.2(5.7)$ & 1 & 4.22 & .12 & $.04^{*}$ \\
\hline
\end{tabular}

Note: ${ }^{*} p<.05$. This study analyzed inquiry-based instruction in English Language Arts/Social Studies.

\subsection{Research Question \#2}

How do the students in the treatment group perceive the effects of inquiry learning on their language and cognition compared to the control group receiving problem-solving instruction?

The first question on questionnaire \#1 distributed in the fall and spring asked students to describe their favorite and least favorite way to learn. Most (30 out of 32) students in both the treatment group and control groups felt that their favorite way to learn was to listen to interactive lectures on various topics and attend field trips. In addition, most (20 out of 32) students in both groups felt that their least favorite way to learn was to memorize math facts and grammar rules, write irrelevant essays, and read boring textbooks. There were no response differences between the fall and spring questionnaires on this item, supporting Dewey's (1916) notion that learning is not merely a process of transmitted knowledge - it is a two-way negotiation of "knowing" that is socially constructed.

The second question on questionnaire \#1 asked students to define what it means to do research. In the fall all students in both groups used typical problem-solving terms to describe research. One girl wrote, "I searched for information on the internet." Another wrote, "I looked up words on a computer." A third student wrote, "I looked up information in a book.”

On the spring questionnaire, while all of the students in the control group continued using traditional problem-solving terms to describe their research experience, many (13 out of 16) students in the treatment group began using terms more explicitly associated with inquiry-based instruction. One girl wrote, "I chose an interesting essential question." A boy wrote, "I found out cool facts because I dug deeper into the topic." Another boy wrote, "I built a project and presented it to the whole class and I had a lot of fun." These responses exemplified learning in Stripling's (2003) wonder, investigate, construct, express, reflect, and connect phases of inquiry instruction. They were also indicative of Dewey's (1916) belief that the mind is not developed through memorization of isolated facts. Rather, it exercises itself through direct application and "response to present stimuli” (p. 73). 
The third question on questionnaire \#1 asked students to describe their biggest challenges in bilingual learning and the difficulties they encountered when doing research in two languages. Most (29 out of 32) students in both groups identified few challenges in bilingual learning and research on both the fall and spring questionnaires. Identified challenges were associated with second language comprehension in reading and writing. One boy in the treatment group wrote, "I felt confused when I read in French because I didn't understand all of the vocabulary." No students in the control group indicated that their bilingualism affected their research ability. However $81 \%$ (13 out of 16) of the students in the treatment group reported that it was easier to do research bilingually because multiple sources in two languages increased their information access.

In the spring distribution of questionnaire \#1, two additional questions were given to the treatment group related to inquiry learning. The first question asked students what they learned by doing inquiry research. Most (15 out of 16) students reported that they better understood the research process because they got to pose their own questions, and answer them using various bilingual resources.

The second question asked students what they liked best about inquiry learning. Most (12 out of 16) students favored activities in the wonder, construct and express phases of Stripling's inquiry process. One student wrote, "I'm glad I got to choose my own topic." Other students wrote about how much they enjoyed sharing their new learning with others.

When asked what they liked least about inquiry learning many (6 out of 16) students expressed frustration during the investigative phase. One student wrote, "I struggled to find information related to my question." Another wrote, "I had a hard time combining all of my little questions into one essential question." A third student wrote, "It was hard for me to read the reference books. I didn't understand all of the words.”

More than half (14 out of 16) of the students in the treatment group stated that they enjoyed everything about inquiry research. Their words described classic reflective thinking that embedded throughout the Stripling (2003) model. They also embodied what Dewey (1916) describes as "the joy of intellectual constructiveness - of creativeness" (p. 88).

Questionnaire \#2 was distributed in the late spring. Each question on this Likert-type questionnaire asked students to support their response with examples. The first question examined how classroom research activities affect learning. Descriptive analysis reported that both groups of students felt that all of the research activities helped them learn (Treatment $M=1.8$, Control $M=1.6$ ). No students in the control group supported their responses with examples. Over half (9 out of 16) of the students in the treatment group supported their responses with examples reporting that their research activities helped them direct their own learning. Content analysis of the student examples indicated that many (14 out of 16) experienced improved subject matter comprehension, enhanced technology skills, better understanding of bilingual conversations with their parents, and higher confidence levels in class presentations. One boy in the treatment group wrote, "I got to direct my learning so I felt more confident about what I learned." Another stated, "When I was having dinner with my dad and I told him about my inquiry research question and we had an actual conversation that rarely happens." A third student wrote, "Inquiry research is a fun and educational way of learning. I would rather do inquiry research than a worksheet.”

The second question on questionnaire \#2 asked students to rank how well the research activities influenced the students' motivation to learn. A Likert-type questionnaire provided the following choices: 1=strongly agree, $2=$ agree, $3=$ neutral, $4=$ disagree, $5=$ strongly disagree. Although significance was not found in the data analysis, descriptive analysis of the questionnaire reported that 15 out of 16 students in the treatment group (compared to 10 out of 16 students in the control group) strongly agreed or agreed with the statement "My research activities positively influenced my motivation to learn."

Short answer responses to the second question further clarified and supported these results. Responses to the statement "My research activities influenced my motivation to learn" tended to be very general in nature for the control group. Content analysis revealed that most (14 out of 16) students desired to learn through research. One boy wrote, "I liked doing research about famous people because it helped me learn more facts." A girl wrote, "Reading about my famous African American made me want to learn more about his life."

In contrast most (14 out of 16) of the short answer responses from the treatment group reflected an awareness of the differences between inquiry-based and traditional problem-solving research processes. One boy wrote,

Well, I feel more confident about doing research on my own now. When its something I like, I go home and look up more things about it. Like when we were reading Time Magazine for Kids about animals and humans communicating together. I liked it and I learned that dogs have lots of ways to tell you they are sad or hungry or tired. Then I went 
home and started looking up more answers to my questions.

Another girl in the treatment group wrote, "The inquiry research project helped me learn how to read even better. That is what affected my learning the most."

Most (12 out of 16) students in the treatment group reported that inquiry-based research activities provided a deeper understanding of the topic, increased reading comprehension, and improved my vocabulary in both languages. One girl wrote, "Well, I learned things that related to what we were learning in French, so I comprehended more. I think it's because I learned words in my research that have some French roots." Another boy expressed his ability to use metalinguistic competencies across each language as they exist in what Cummins (1981) refers to as Common Underlying Proficiency (CUP),

If I research in English, I think in English. If I research in French, I think 85\% in French. I don't think researching in English makes you think in French or vice versa. For example when I researched for the Airpod, the website was in French, so I had to convert it to English to use the information in my presentation, which proves that I think in each language separately.

\section{Discussion}

The results of this study provide a deeper understanding of effective instruction for bilingual children. The researchers explored how inquiry-based instruction affected the overall academic achievement of thirty-two $5^{\text {th }}$ graders in a French dual immersion program. Although there was no statistical significance to report on between group effects on the CTP4 subtest for Mathematical Reasoning the repeated ANOVA findings reported a significant finding on tests of within-subject effects in favor of the treatment group (see Table 1). The significant interaction indicated that the treatment group math scores increased at a faster rate over time.

Although both groups were exposed to the same mathematics curriculum in the same class, the positive effect of inquiry-based instruction on the mathematical reasoning of the treatment group could possibly be explained by skills students attained through inquiry learning in their English/Social Studies class. In the inquiry learning environment students in the treatment group may have experienced what Stripling (2003) describes is a recursive "relationship between thinking skills and content” (p. 6). Students were not just passively constructing knowledge by searching for answers to problems - a practice commonly found in the problem-solving approach for mathematics and science. They were practicing what Kharkhurin (2007) describes as enhanced divergent thinking ability and cognitive control often experienced by bilinguals exposed to such tasks.

Recent studies in mathematic achievement among elementary aged children found a significant correlation between divergent thinking and mathematical achievement (Bahar \& Maker, 2011). Through inquiry learning the treatment group of students in this study actively engaged in subject matter study, which may have deepened their content knowledge, and strengthened the critical thinking processes needed to solve complex problems in mathematics. The learning that transferred between subjects potentially activated what De Corte (2007) refers to as "adaptive expertise" (p.21), thus preparing students for new learning. Posing questions, synthesizing relevant information, and forming plausible conclusions possibly motivated student confidence, and catalyzed essential cognitive reasoning skills.

The effects of inquiry learning also had a positive effect on the treatment group's English/French bilingual verbal ability (BVA), which increased at a significantly faster rate than the control group of students. The BVAT Comprehensive Manual (Muñoz-Sandoval, Cummins, Alvarado, \& Ruef, 1998) explains that bilingual verbal ability represents the verbal, and cognitive ability that is distributed across different domains of a child's L1 and L2.

The significant increase in bilingual verbal ability experienced by the treatment group could possibly be explained by enhanced executive functioning, strengthened through inquiry-learning tasks, that activated students' heightened bilingual ability to monitor their environment. Collective evidence from a number of studies suggest that when bilingual children are engaged in active learning environments they experience finely tuned metalinguistic awareness and attention processes used for planning, increased cognitive flexibility, multicompetence in problem solving, and the ability to form conclusions utilizing divergent, and convergent thinking (Kharkhurin, 2008; Bialystok, 2006). A recent meta-analysis of multilingual research (European Commission, 2009) reported that when multilingual children experience enhanced executive functioning, they demonstrate an increase in "abstract thinking skills, creative hypothesis formulation, higher concept formation skills, and overall higher mental flexibility” (p. 11). Through guided inquiry learning the students in the treatment group learned how to interpret, and process information through student centered investigations that taught them how to discern important from unimportant questions and facts. This process likely activated strategic bilingual problem solving competence that led to an increase in bilingual verbal 
cognitive ability.

The data regarding student program perceptions indicated that both the control and treatment group of students preferred active, teacher guided learning activities. Although both groups specified that research activities strongly correlated with their learning, students in the treatment group reported a better understanding of the research process because instruction specifically targeted the development of metacognitive processes and self-regulatory capabilities.

As the treatment group of students directed their own research inquiries they reported increased self-efficacy, and a stronger motivation to learn, or what Dewey (1916) describes as "creativeness" (p. 88), or the ability to problem solve using original thoughts. This could possibly be explained by the constructivist philosophy embedded in the inquiry learning approach. Inquiry learning taught children how to regulate their behaviors. They learned such strategies as predicting outcomes, planning ahead, time management, comprehension monitoring, and how to use background knowledge. These metacognitive processes and self-regulatory capabilities were not developed in the problem-solving learning experiences of the children in the control group.

\section{Limitations of the Study}

Several limitations found in this study preclude generalizability in its findings. The small sample size limited the statistical power in the treatment group's increased mathematical reasoning, and bilingual verbal development; therefore generalizations cannot be made to broader bilingual student populations without further research.

Another limitation of the study was found in the narrow linguistic and sociocultural demographics of the participants. All of the children in the study came from high socioeconomic backgrounds with highly educated parents. They were all proficient bilinguals with above average competence in English. Additionally, all of the children were enrolled in a dual immersion program that valued their bilingual competence, and increased their perceived student status.

Although the limitations found in this study were significant, the conclusions support its micro analytical design. They provided the researchers with an in depth understanding of effective instructional differences that may not have occurred in more varied contexts.

\section{Conclusion}

The inquiry-based instructional approach described in this study supports our current understanding of how people learn. Stimulating learning environments that pique students' natural curiosity are linked to issues that are especially important in processes of bilingual cognition and competence. These processes seem to be positively or negatively affected by the degree to which learning is student-centered, knowledge-centered, community-centered and authentically assessed.

Recommendations for future research include: a) extending the study to a broader context in diverse school settings, (b) examining the cognitive effects of inquiry learning on bilingual children enrolled in English only programs, and (c) studying the effects of inquiry-based instruction on the academic language use of ELLs who are partial bilinguals. This study examined the effect of inquiry learning on a very narrow pool of proficient bilinguals with high cognitive and socioeconomic advantages. Because the results suggested a positive effect on students' bilingual verbal ability and mathematics reasoning skills, the researchers would like to observe the cognitive effects of inquiry learning in bilingual students with lower socioeconomic status who struggle to succeed in public school English immersion programs. Because of the new emphasis on the Common Core Standards, it would be also be interesting to study the program's effect on student reasoning and higher order thinking skills in such contexts.

Effective instruction for all students begins with acknowledging the child's inherent need to explore the world. Teaching to the child's curious bent celebrates individual student interests, and levels of understanding for all children. Creative educational experiences crafted within an authentic community context enable students to build a body of shared knowledge that motivates future learning. Inquiry-based instruction provides an empowering platform for all children to exercise their natural curiosity, and simultaneously increase cognitive abilities in an increasingly globalized world.

\section{Acknowledgements}

The authors thank the subjects whose participation made this study possible. We also thank P. Boustiha for individually administering the pre/post French BVAT subtest to each student in the study, and M. France, who provided assistance with statistical data analysis. This research was supported through a Dean's Grant from the 
Education Department at Santa Clara University.

\section{References}

Alanís, L. (2011). Learning from each other: Bilingual pairs in dual-language classrooms. Dimensions of Early Childhood, 39(1), 21-28.

Amaral, O.M., Garrison, L., \& Klentschy, M. (2002). Helping English learners increase achievement through inquiry-based science instruction. Bilingual Research Journal, 26(2), 213-239. http://dx.doi.org/10.1080/15235882.2002.10668709

Bahar, A.K., \& Maker, C.J. (2011). Exploring the relationship between mathematical creativity and mathematical achievement. Asia-Pacific Journal of Gifted and Talented Education, 3(1), 33-48.

Bialystok, E. (2006). Effect of bilingualism and computer video game experience on the Simon task. Canadian Journal of Experimental Psychology, 60, 68-79. http://dx.doi.org/10.1037/cjep2006008

Castronova, J.A. (2002). Discovery learning for the $21^{\text {st }}$ century: What is it and how does it compare to traditional learning in effectiveness in the $21^{\text {st }}$ century? Action Research Exchange, 1(1), 1-12.

Chu, K.W.S. (2009). Inquiry project based learning with a partnership of three types of teachers and the school librarian. Journal of the American Society for Information Science and Technology, 60(8), 1671-1686. http://dx.doi.org/10.1002/asi.21084

Chu, S., Chow, K., Luk, W. Y., Cheung, K., \& Sit, D. K. N. (2007). The development of primary four students' information literacy and information technology skills. Paper presented at the Conference on Integrated Learning. Hong Kong: The Hong Kong Institute of Education December.

Chu, S., Tse, S.K., Loh, E., \& Chow, K. (2011). Collaborative inquiry project-based learning: Effects on reading ability and interests. Library and Information Science Research, 33, 236-243. http://dx.doi.org/10.1016/j.lisr.2010.09.008

Copsey Haydey, D., Zakaluk, B.L., \& Straw, S. (2010). The changing face of content area teaching. Journal of Applied Research on Learning, 3(3), 1-29.

Cummins, J. (1981). The role of primary language development in promoting educational success for language minority students. In California State Department of Education (Ed.), Schooling and language minority students: A theoretical framework. (pp. 3-49). Los Angeles: Evaluation, Dissemination and Assessment Center, California State University.

De Corte, E. (2007). Learning from instruction: The case of mathematics. Learning Inquiry, 1(1), 19-30. http://dx.doi.org/10.1007/s11519-007-0002-4

De Groot. (2011). Language and Cognition in Bilinguals and Multilinguals. New York, NY: Psychology Press.

Dewey, J. (1916). Democracy and education. New York: Macmillan.

Educational Records Bureau (2002). CTP 4 Content Standards Manual. New York, NY: Educational Records Bureau.

European Commission (July 2009). Multilingualism and creativity: Towards an evidence-base. Brussels, Belgium: Commission of the European Communities.

Fouratt, S., \& Owen, C. (2004). CTP 4, Comprehensive testing program 4 [Technical Report]. Princeton, NJ: Educational Testing Service.

Giorgi, A. (1975). An application of phenomenological method in psychology. In A. Giorgi, C. Fischer, and E.L. Murray (Eds.), Duquesne studies in phenomenological psychology. (Vol. 2, pp. 82-103). Pittsburgh, PA: Duquesne University Press. http://dx.doi.org/10.5840/dspp197529

Kharkhurin, A. (2008). The effect of linguistic proficiency, age of second language acquisition, and length of exposure to a new cultural environment on bilinguals' divergent thinking. Bilingualism: Language and Cognition, 11(2), 225-243. http://dx.doi.org/10.1017/S1366728908003398

Krippendorff, K. (1980). Content analysis: An introduction to its methodology. Newbury Park, CA: Sage.

Laija-Rodríguez, W., Ochoa, S.H., \& Parker, R. (2006). The crosslinguistic role of cognitive academic language proficiency on reading growth in Spanish and English. Bilingual Research Journal: The Journal of the National 
Association for Bilingual Education, 30(1), 87-106. http://dx.doi.org/10.1080/15235882.2006.10162867

Lee, V. (2011). The power of inquiry as a way of learning. Innovative Higher Education, 36, 149-160. http://dx.doi.org/10.1007/s10755-010-9166-4

Litman, J. (2005). Curiosity and the pleasure of learning: Wanting and liking new information. Cognition and Emotion, 19(6), 793-814. http://dx.doi.org/10.1080/02699930541000101

Maata, D., Dobb F., \& Ostlund K. (2006). Strategies for teaching science to English learners. In A. Fathman and D. Crowther, (eds.), Science for English language learners, 37-59. Arlington: NSTA Press.

McNally, M.J. (2005). Analysis of students' mental models: Using the Internet in an authentic learning situation. Dissertation Abstracts International, 66(5), 1541A. (UMI No. 3176205).

Miles, M.B., \& Huberman, A.M. (1994). Qualitative data analysis: An expanded sourcebook (2 ${ }^{\text {nd }}$ Ed.). Thousand Oaks, CA: Sage Publications.

Milligan, J.R. (1979). Schema learning theory: An approach to perceptual learning. Review of Educational Research, 49(2), 197-207. http://dx.doi.org/10.3102/00346543049002197

Moses, L., Busetti-Frevert, R., \& Pritchard, R. (2015). Inquiry as ESL: Supporting emerging bilinguals’ content and language development. The Reading Teacher, 68(6), 435-447. http://dx.doi.org/10.1002/trtr.1333

Muñoz-Sandoval, A.F., Cummins, J., Alvarado, C.G., \& Ruef, M.L. (1998). Bilingual Verbal Abilities Tests. Rolling Meadows, IL: Riverside Publishing.

Ortíz, S.O. (2002). Best practices in non-discriminatory assessment. In A. Thomas, \& J. Grimes (Eds), Best practices in school psychology - IV (pp. 1321-1336). Washington DC: National Association of School Psychologists.

Stoddart, T., Bravo, M., Solis, J.L., Mosqueda, E., \& Rodriguez, A. (2011). Effective science teaching for English language learners (ESTELL): Measuring pre-service teacher practices. Paper presented at the annual meeting of the American Educational Research Association, New Orleans.

Stripling, B.K. (2003). Inquiry-based learning. In B.K. Stripling \& S. Huges-Hassell (Eds.), Curriculum Connections through the Library (3-39). Westport, CT: Libraries Unlimited.

Weber, R.P. (1990). Basic content analysis $\left(2^{\text {nd }}\right.$ ed.). Newbury Park, CA: Sage Publications. http://dx.doi.org/10.4135/9781412983488

Weinburgh, M., Silva, C., Smith, K.H., Groulx, J., \& Nettles, J. (2014). The intersection of inquiry-based science and language: Preparing teachers for ELL classrooms. Journal of Science Teacher Education, 25(5), 519-541. http://dx.doi.org/10.1007/s10972-014-9389-9

Westerveldt, M. (2007). Schoolyard inquiry for English language learners. The Science Teacher, 47-51.

Wiggins, G., \& McTighe, J. (1998). Understanding by design. Alexandria, VA: Association for Supervision and Curriculum Development.

Williams, J., \& Lombrozo, J. (2010). The role of explanation in discovery and generalization: Evidence from category learning. Cognitive Science, 34, 776-806. http://dx.doi.org/10.1111/j.1551-6709.2010.01113.x

Woodcock, R.W. (1991). Woodcock language proficiency battery-revised. Rolling Meadows, IL: The Riverside Publishing Company.

Woodcock, R.W., \& Johnson, M.B. (1989). Woodcock-Johnson-revised tests of cognitive ability. Rolling Meadows, IL: The Riverside Publishing Company.

Yamashita, J. (2002). Mutual compensation between L1 reading ability and L2 language proficiency in L2 reading comprehension. Journal of Research in Reading, 25(1), 81-95. http://dx.doi.org/10.1111/1467-9817.00160 